\title{
FANCC Gene Mutation
}

National Cancer Institute

\section{Source}

National Cancer Institute. FANCC Gene Mutation. NCI Thesaurus. Code C131792.

A change in the nucleotide sequence of the FANCC gene. 